\title{
Development of a Suitable Technique of Estimating Soluble Sulphur Using Less Health Hazardous Chemical
}

\author{
Tirthankar Bhandary, Abhijit Pal*, Saurabh Mathur, Maitreya Dutta, Saikat Dasgupta and \\ Rabindra Mukhopadhyay \\ Hari Shankar Singhania Elastomer and Tyre Research Institute (HASETRI), Raghupati Singhania Centre of Excellence, 437, \\ Hebbal Industrial Area, Mysore-570016, Karnataka, India
}

*Corresponding author: Abhijit Pal, Hari Shankar Singhania Elastomer and Tyre Research Institute (HASETRI), Raghupati Singhania Centre of Excellence, 437, Hebbal Industrial Area, Mysore-570016, Karnataka, India

\section{ARTICLE INFO}

Received: 蔧 April 28, 2021

Published: May 05, 2021

Citation: Tirthankar B, Abhijit P, Saurabh M, Maitreya D, Saikat D, Rabindra M. Development of a Suitable Technique of Estimating Soluble Sulphur Using Less Health Hazardous Chemical. Biomed J Sci \& Tech Res 35(4)-2021. BJSTR. MS.ID.005721.

\section{ABSTRACT}

Development of suitable analytical method is important for a specific measurement. At the same time the method has to be validated to confirm the suitability for the intended use. The quality, consistency and reliability of the test result can be judged by the typical method validation characteristics through repeatability, detection limit, quantitation limit, working range in terms of linearity, trueness, bias, recovery etc. Liquid chromatographic technique has been used in the current study to estimate the soluble sulphur content in rubber chemical sulphur by the use of less quantity chemical having comparatively less health hazards.

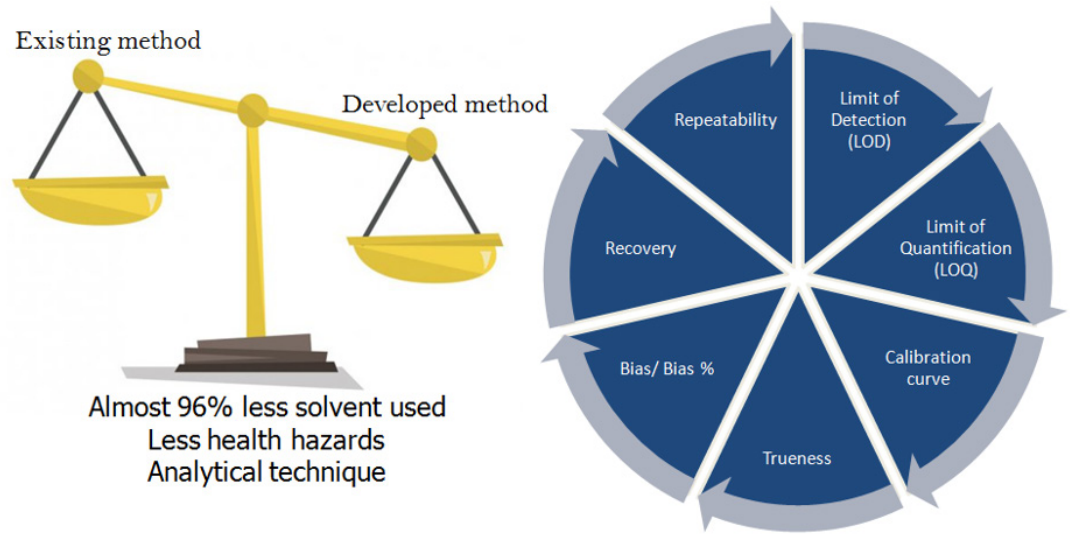

Graphical Abstract.

Keywords: Method Development; Working Range; Repeatability; Detection Limit; Quantification Limit

Abbreviations: ISO: International Organization for Standardization; ASTM: American Society for Testing and Materials; IS: Indian Standard; NBS: National Bureau of Standards; CNS: Central Nervous System; HPLC: High Performance Liquid Chromatography 


\section{Introduction}

An analytical method is a process or pathway to estimate, determine, or solve any type of measurand or problem or product [1,2]. It needs some instruments, tools, glassware, mathematical theorems to solve the problem [3]. Various national and international bodies, e.g. International Organization for Standardization (ISO), European Committee for Standardization (CEN), American Society for Testing and Materials (ASTM), Indian Standard (IS), National Bureau of Standards (NBS) are involved in this work to create standard analytical methods with respect to quality and reliability [4,5]. In rubber industry various standard methods are used for testing purpose such as characterization of incoming raw materials as well as in process materials, and finished products [6]. Such a method is ASTM D4578: "Standard Test Method for Rubber Chemicals - Determination of Percent Sulfur by Extraction [7]." At rubber product manufacturing units, Sulfur is used as curing or vulcanizing or cross-linking agent $[8,9]$. Two allotropes of Sulfur are used: soluble Sulfur $\left(\mathrm{S}_{8}\right.$ crown $)$ and insoluble Sulfur (polymeric) [10]. For better performance of rubber product, insoluble Sulfur is preferred during rubber compounding $[11,12]$. Use of soluble Sulfur in rubber matrix leads to blooming phenomena and also makes the rubber product more prone to oxygen and ozone attacks $[11,13]$.

It is essential to quantify the fraction of soluble Sulfur present in the total Sulfur to be used for curing purpose [14]. The $\mathrm{S}_{8}$ allotrope of Sulfur is soluble in Carbon disulfide $\left(\mathrm{CS}_{2}\right)$ and Toluene $\left(\mathrm{C}_{6} \mathrm{H}_{5} \mathrm{CH}_{3}\right)$ [15]. In the ASTM D4578 method, one of these two solvents is used for extraction purpose, leaving behind the insoluble material. Total amount of solvent required for extraction is 100 to 150 $\mathrm{ml}$ over a minimum extraction period of 8 minutes [7]. $\mathrm{CS}_{2}$ is a colourless, highly volatile, obnoxiously odorous, flammable, toxic liquid solvent having both acute and chronic toxicity. Exposure of $\mathrm{CS}_{2}$ having concentration of $10 \mathrm{ppm}$ or more in atmosphere may lead to numbness, blurred vision, cramps, muscle fatigue, neurophysiological impairment, psychosis, keratitis, priapism, erectile dysfunction, and death by respiratory failure [16]. On the other hand for acute (short-term) and chronic (long-term) exposure of toluene toxicity, affect Central Nervous System (CNS) primarily in both humans and animals. Acutely exposed to elevated airborne levels of toluene; symptoms include fatigue, sleepiness, headaches, and nausea [17].

We have developed liquid chromatographic [High Performance Liquid Chromatography (HPLC)] technique as a successful analytical method for the estimation of soluble sulphur content in total sulfur. Here also we have used toluene but very less quantity $(5 \mathrm{ml})$ is sufficient to get repeatable and reliable result. Necessary study has been done to establish as a successful validated method [18].

\section{Material and Method}

\section{Materials}

HPLC grade toluene and methanol were procured from Merck India. Double distilled deionised water was prepared in Millipore water system, Elga, USA. Soluble sulphur (CAS No.: 7704-34-9, Product No. 84683) having purity more than $99.5 \%$ has been procured from Sigma Aldrich. Waters glass vials were used for sample and standard solution preparation. Borosil micropipette and volumetric flask were used for volume measurement and standard solution preparation. Ministar syringe filter was used for sample solution filtration. All chemicals were used without further treatment and purification.

\section{Instrument}

Liquid chromatography model: Alliance HPLC System, Waters e2695 separations module with 2998 PDA detector was procured from Waters India Pvt Ltd, Bangalore. The instrument parameters were set as:

a. Column C18: pore size $100 \AA$, particle size $5 \mu \mathrm{m}$, inner diameter $4.6 \mathrm{~mm}$ and length $250 \mathrm{~mm}$

b. Column temp: $40^{\circ} \mathrm{C}$

c. Injection volume: $10 \mu \mathrm{l}$

d. Sampling type: Auto sampler

e. Solvent A: 100\% Methanol

f. Solvent B: $100 \%$ water

g. Total flow rate: $1.3 \mathrm{ml} / \mathrm{min}$

h. Flow detail: 98\% Pump A + 2\% Pump B (Isocratic)

i. Detector Wavelength: $285 \mathrm{~nm}$

\section{Method}

A set of calibration standards (Table 1) solution have been prepared by dissolving pure soluble sulphur in $5 \mathrm{ml}$ HPLC grade toluene. The solution has been filtered through syringe filter and injected in HPLC using the above program (Section 2.2). A typical HPLC chromatogram has been shown in Figure 1. First peak at $\sim 2.3$ min represents elution of toluene and the second peak at $\sim 5.6$ min was for soluble sulphur. The area under the second peak was epitomized to soluble sulphur was taken with respect to the concentration of the sulphur separately for each prepared calibration solutions. A calibration curve between area under the curve and concentration of soluble sulphur was drawn. From the obtained linear equation, soluble sulphur content in test specimen has been estimated. 


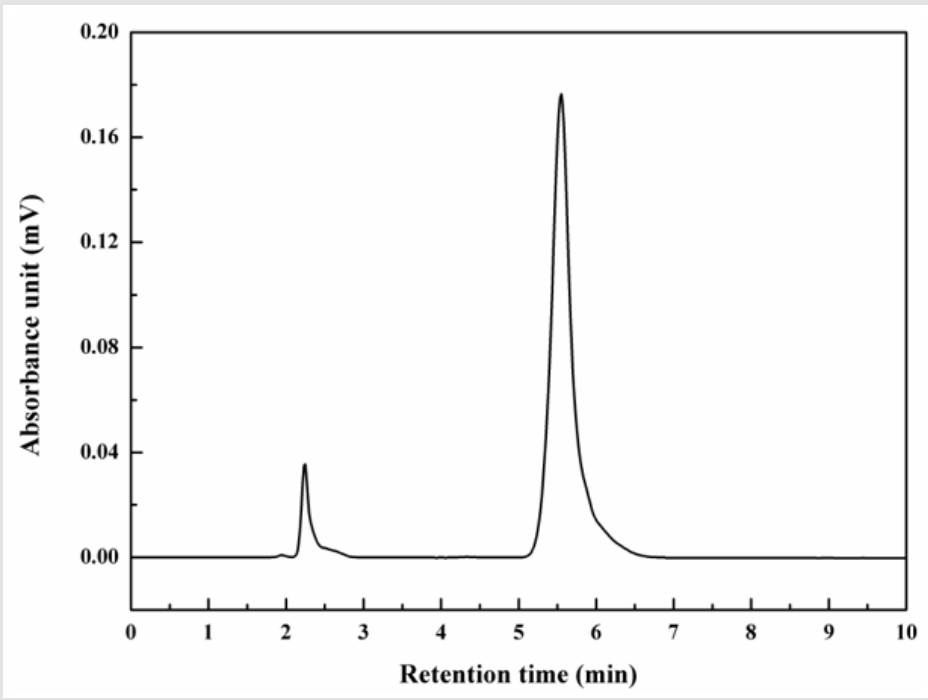

Figure 1: A typical HPLC chromatogram of soluble sulphur.

Table 1: Calibration standard solution preparation.

\begin{tabular}{|c|c|}
\hline Sl. No. & Concentration of Soluble Sulphur $\mathbf{( m g / m l )}$ \\
\hline 1 & 0.096 \\
\hline 2 & 0.194 \\
\hline 3 & 0.342 \\
\hline 4 & 0.569 \\
\hline 5 & 1.087 \\
\hline 6 & 1.257 \\
\hline
\end{tabular}
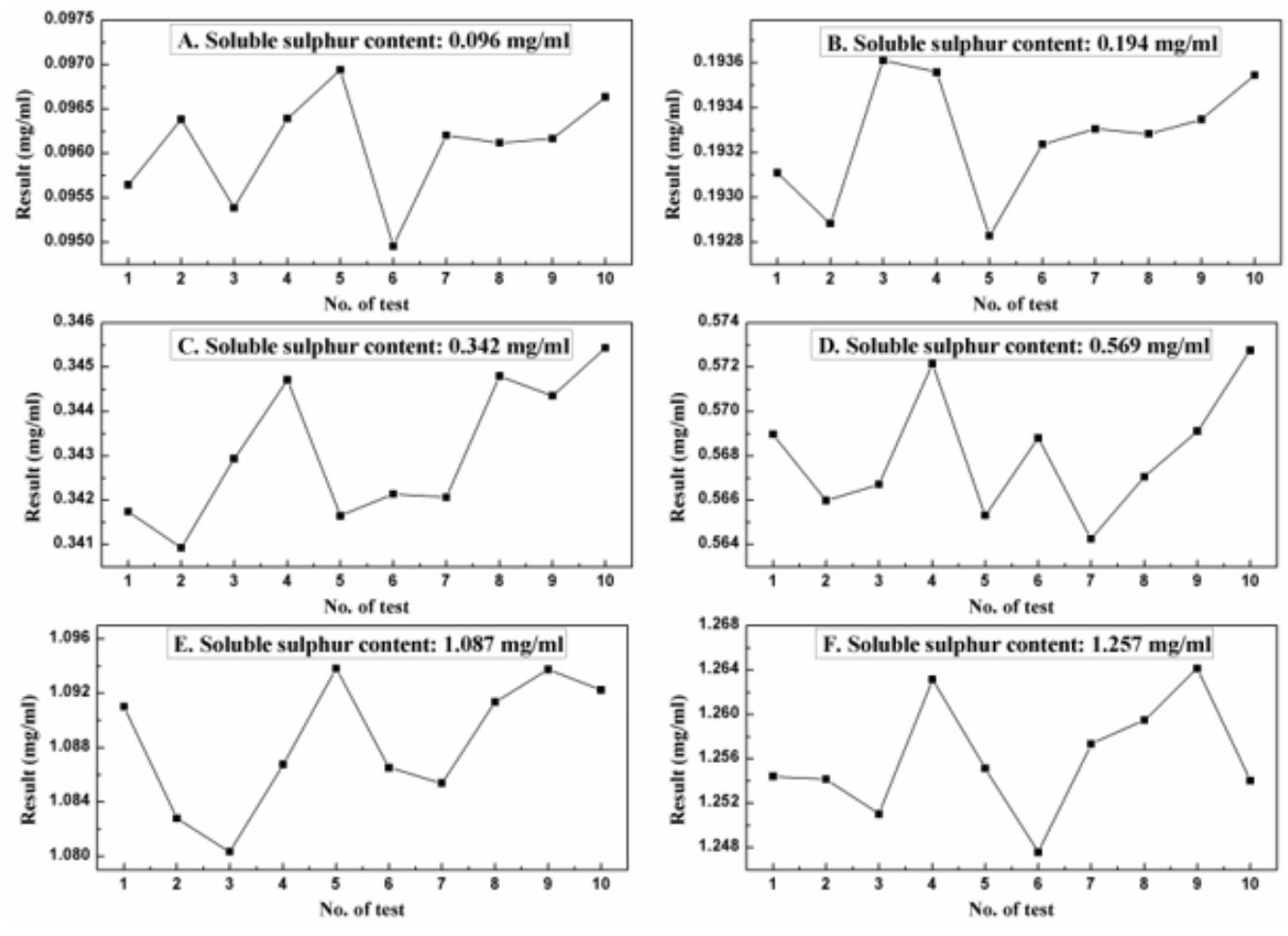

\section{Repeatability Measurement}

It is the experiment performed under a set of similar condition to evaluate how repeatable the results are. Ten replicate tests of each calibration standard samples have been analysed to study the repeatability of developed technique and results are tabulated in Table 2 and all results have been plotted separately in Figures 2A$2 \mathrm{~F}$. The closeness of the results clearly indicates the repeatable data obtained in all cases.

Figure 2: Replicate test result of each calibration standard solution. 
Table 2: Ten replicate test results of calibration standard and LOD, LOQ calculation.

\begin{tabular}{|c|c|c|c|c|c|c|}
\hline Actual Conc. (mg/ml) & 0.096 & 0.194 & 0.342 & 0.569 & 1.087 & 1.257 \\
\hline Test 1 Conc. (mg/ml) & 0.096 & 0.193 & 0.342 & 0.569 & 1.091 & 1.254 \\
\hline Test 2 Conc. (mg/ml) & 0.096 & 0.193 & 0.341 & 0.566 & 1.083 & 1.254 \\
\hline Test 3 Conc. (mg/ml) & 0.095 & 0.194 & 0.343 & 0.567 & 1.08 & 1.251 \\
\hline Test 4 Conc. (mg/ml) & 0.096 & 0.194 & 0.345 & 0.572 & 1.087 & 1.263 \\
\hline Test 5 Conc. $(\mathrm{mg} / \mathrm{ml})$ & 0.097 & 0.193 & 0.342 & 0.565 & 1.094 & 1.255 \\
\hline Test 6 Conc. (mg/ml) & 0.095 & 0.193 & 0.342 & 0.569 & 1.087 & 1.248 \\
\hline Test 7 Conc. (mg/ml) & 0.096 & 0.193 & 0.342 & 0.564 & 1.085 & 1.257 \\
\hline Test 8 Conc. $(\mathrm{mg} / \mathrm{ml})$ & 0.096 & 0.193 & 0.345 & 0.567 & 1.091 & 1.259 \\
\hline Test 9 Conc. $(\mathrm{mg} / \mathrm{ml})$ & 0.096 & 0.193 & 0.344 & 0.569 & 1.094 & 1.264 \\
\hline Test 10 Conc. (mg/ml) & 0.097 & 0.194 & 0.345 & 0.573 & 1.092 & 1.254 \\
\hline Average & 0.096 & 0.193 & 0.343 & 0.568 & 1.088 & 1.256 \\
\hline SD at lowest conc. & \multicolumn{6}{|c|}{0.001} \\
\hline Slope & \multicolumn{6}{|c|}{1.000055236} \\
\hline LOD (mg/ml) & \multicolumn{6}{|c|}{0.002} \\
\hline $\mathrm{LOQ}(\mathrm{mg} / \mathrm{ml})$ & \multicolumn{6}{|c|}{0.006} \\
\hline
\end{tabular}

\section{Limit of Detection (LOD) and Limit of Quantification} (LOQ)

Limit of detection is defined as the lowest concentration of an analyte in a sample that can be detected, though not necessarily quantitated. Limit of quantitation is defined as the lowest concentration of an analyte in a sample that can be determined with acceptable precision and accuracy understated operational condition of the method. LOQ is directly proportional to the precision. LOD (Eq. 1) and LOQ (Eq. 2) are calculated from the standard deviation (Eq. 3) at lowest concentration using the following equations [19].

$$
\begin{aligned}
& L O D=3.3 \times \frac{S}{\text { Slope }} \ldots \ldots \ldots \ldots \ldots \ldots \ldots . . . . . . . . .1 \\
& L O Q=10 \times \frac{S}{\text { Slope }} \ldots \ldots \ldots \ldots \ldots \ldots . . . . . . . . . . .2
\end{aligned}
$$

$$
S=\sqrt{\frac{1}{n}} \sum_{i=1}^{n}\left(x_{i}-\mu\right)^{2}
$$

Where,

S: Standard deviation of ten replicates data of lowest calibration standard sample (Table 2)

$\mathrm{x}_{\mathrm{i}}: \mathrm{i}^{\text {th }}$ test result of lowest calibration standard sample

$\mu$ : Mean of ten replicates data of lowest calibration standard sample

$n$ : Number of replicate test performed $(n=10)$

\section{Estimation of Working Range}

Working range of a method defines the interval over which the uncertainty will be acceptable. To estimate the working range, linearity of response obtained from different calibration standards tested and achieved correlation coefficient as 0.9998 . The linearity study has been shown in Figure 3. 


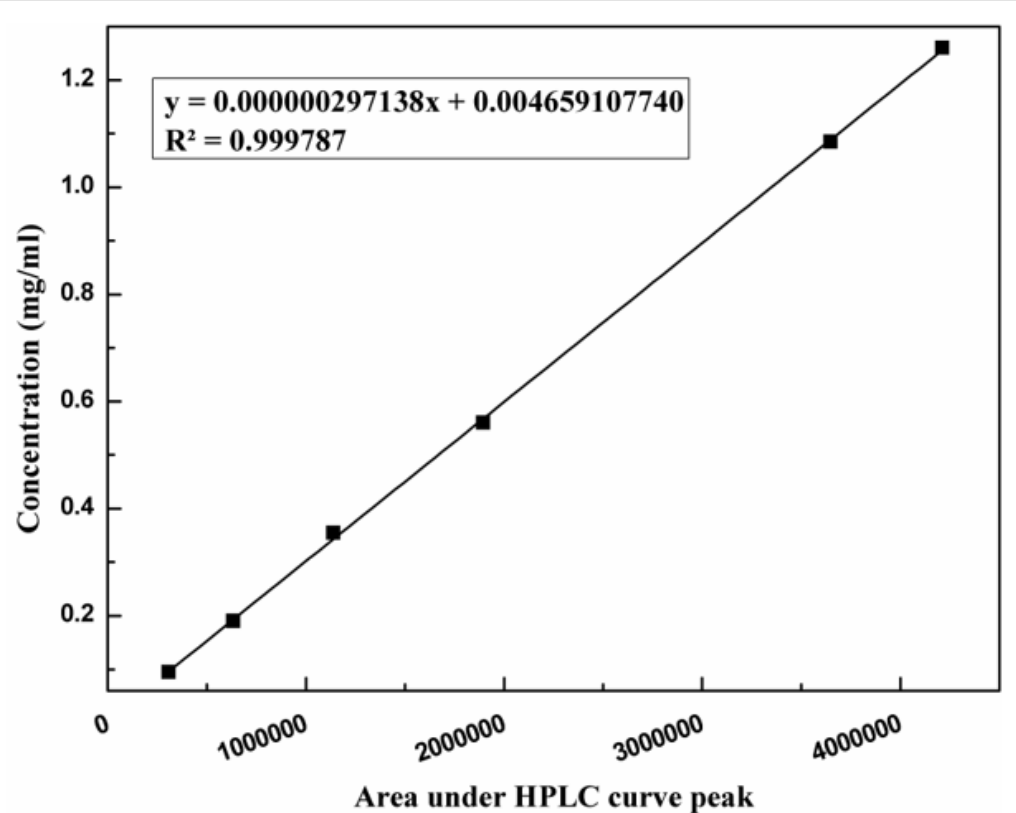

Figure 3: Linear regression model for the estimation of working range.

\section{Trueness}

Trueness is defined as closeness of a single value to the mean of infinite number of result which practically determination is not possible. In place of mean of infinite data i.e. true value, actual metal content in the calibration standard has been considered. Trueness of this method has estimated in term of bias and precision.
Bias is defined as the closeness of the result with true value and can be estimated by three different techniques, (a) analysis of reference material (b) recovery of the analyte (c) comparison of results obtained from different techniques. In this study, the calibration standards have been considered as reference material, bias, percent bias and recovery have been estimated and results are mentioned in Figures 4 \& 5 .

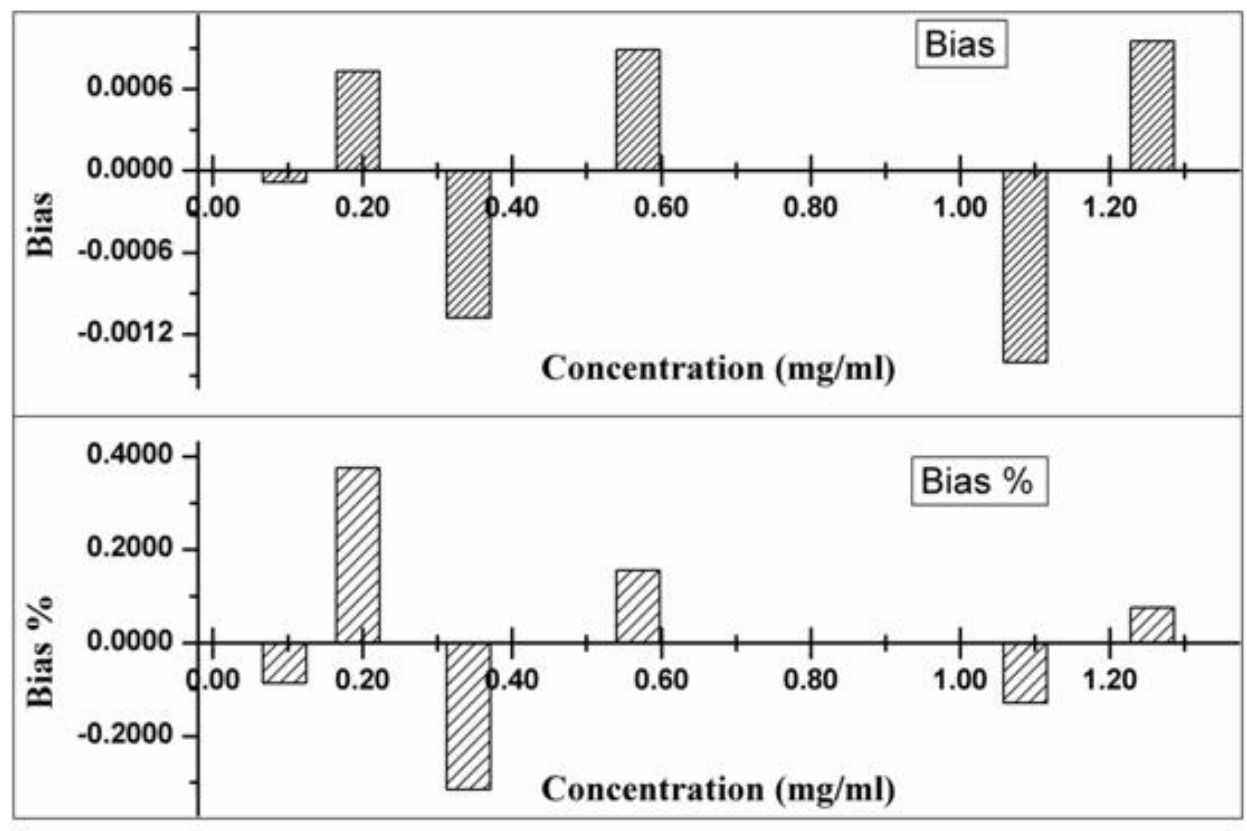

Figure 4: Trueness study in terms of bias and bias \%. 

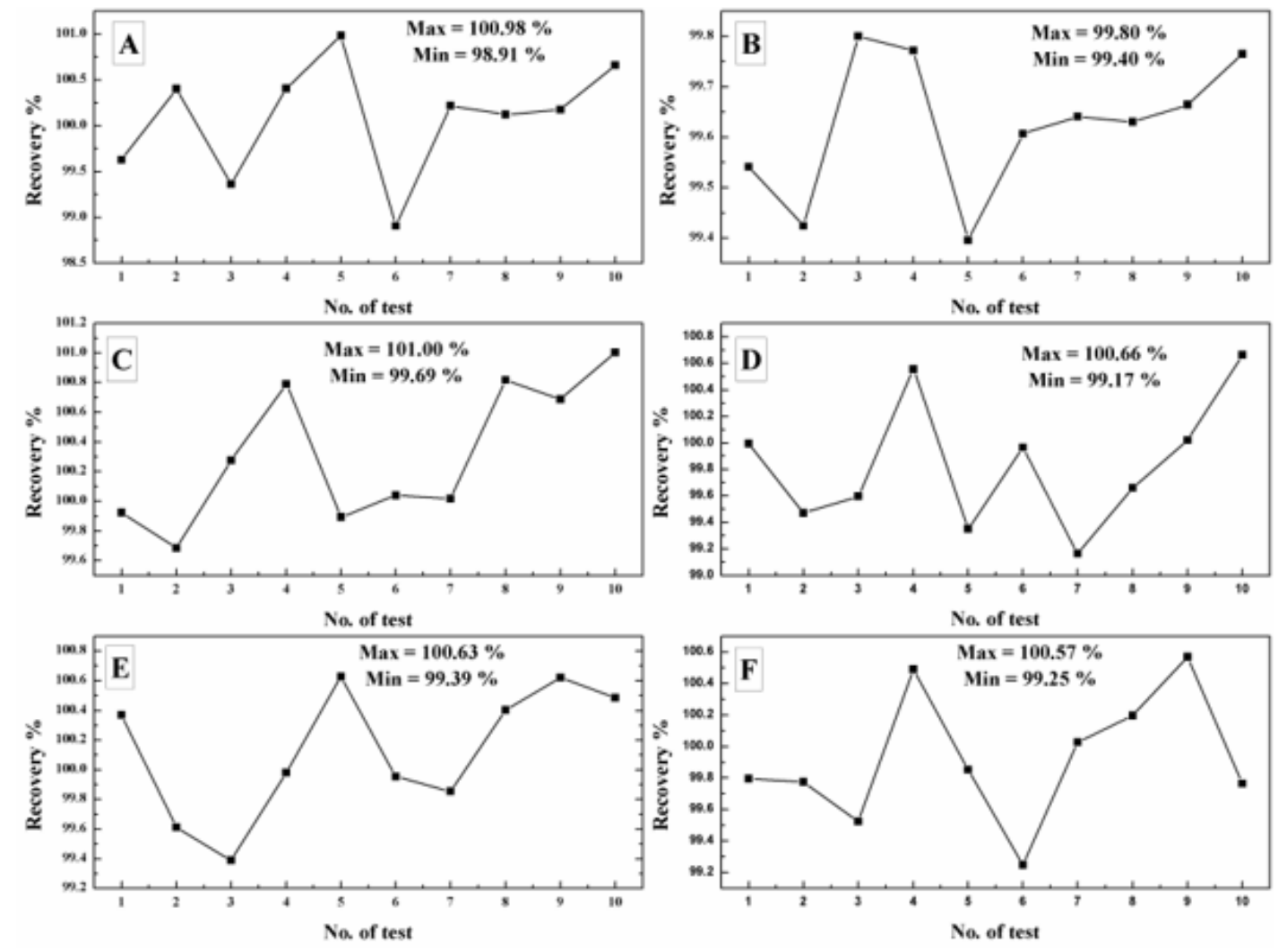

Figure 5: Recovery study of the calibration standard samples.

\section{Conclusion}

While estimating soluble sulphur content using HPLC as a tools, it was found that regression coefficient factor obtained during calibration is 0.9998 which signifies that the developed method is exhibit linear relationship during analysis of standard sample having concentration from $0.096 \mathrm{mg} / \mathrm{ml}$ to $1.257 \mathrm{mg} / \mathrm{ml}$. Trueness study of standard samples indicates both the positive and negative bias obtained during the analysis and the maximum is $0.376 \%$ and $-0.315 \%$ respectively. Recovery in different concentration has been analysed and found it is lying between 98.91\%-101.00\%. The experiment of estimation of limit of detection and limit of quantification confirms that, through this technique, soluble sulphur having concentration $0.002 \mathrm{mg} / \mathrm{ml}$ can be detected in the sample and can be quantified above $0.006 \mathrm{mg} / \mathrm{ml}$. Thus the above technique can be adopted as an analytical method as far as environment point of view with respect health hazardous effect and less quantity chemical use.

\section{Acknowledgement}

The authors wish to acknowledge ISO/IEC 17025:2017 accredited Analytical and Chemical Department, HASETRI and JK Tyre \& Industries for providing the research facility and financial support to undertake the research work.

\section{References}

1. Khusna AH (2020) Analytical thinking process of student in proving mathematical argument. Int J Sci Technol Res 9(1): 1248-1251.

2. Suits LD (2007) National and international standards governing geosynthetics. In: RW Sarsby (Eds.)., Geosynth. Civ Eng. Woodhead Publishing, UK, p. 66-93.

3. Harvey D (2019) Basic Tools of Analytical Chemistry.

4. I Standards. Appendix-International Standards Part B Measurement Methods for Composition and Structure, (n.d.), pp. 1097-1149.

5. Report S (2019) Rubber standards in today's world economy. Rubber Plast News, p. 14-18.

6. Aiza Jaafar CN, Zainol I, Ishak NS, Ilyas RA, Sapuan SM (2021) Effects of the liquid natural rubber (LNR) on mechanical properties and microstructure of epoxy/silica/kenaf hybrid composite for potential automotive applications. J Mater Res Technol 12: 1026-1038.

7. (2017) ASTM D4578-06. Standard Test Methods for Rubber ChemicalsDetermination of Percent Sulfur by Extraction, ASTM Int (n.d.).

8. Kruželák J, Kvasničáková A, Hložeková K, Vilčáková J, Hudec I (2021) Influence of Combined Sulfur and Peroxide Curing Systems and Ageing on the Properties of Rubber Magnets. Macromol Symp 395: 2000258.

9. Vieyres A, Pérez-Aparicio R, Albouy PA, Sanseau O, Saalwächter K, et al. (2013) Sulfur-Cured Natural Rubber Elastomer Networks: Correlating Cross-Link Density, Chain Orientation, and Mechanical Response by Combined Techniques. Macromolecules 46(3): 889-899.

10. Meyer B (1976) Elemental sulfur. Chem Rev 76(3): 367-388. 
11. Rodgers B, Waddell WH, Klingensmith W (2004) Rubber Compounding. Encycl Polym Sci Technol. American Cancer Society.

12. Shahrampour H (2018) Comparison of Sulfur Curing Systems (InsolubleRhombic) on Physical and Thermal Properties of the Matrix Polymeric of Styrene-Butadiene Rubber and Natural Rubber. Pet Chem 58: 721-726.

13. Datta RN, Huntink NM, Datta S, Talma AG (2007) Rubber Vulcanizates Degradation and Stabilization. Rubber Chem Technol 80(3): 436-480.

14. Wręczycki J, Bieliński DM, Anyszka R (2018) Sulfur/organic copolymers as curing agents for rubber. Polymers (Basel) 10(8): 870.

15. Lens P, Pol LWH (2000) Environmental Technologies to Treat Sulfur Pollution. IWA Publishing.

ISSN: 2574-1241

DOI: 10.26717/BJSTR.2021.35.005721

Abhijit Pal. Biomed J Sci \& Tech Res

(c) (P) This work is licensed under Creative

Submission Link: https://biomedres.us/submit-manuscript.php
16. (2021) Carbon disulfide. Wikipedia. Free Encycl (n.d.).

17. Yavari F, Van Thriel C, Nitsche MA, Kuo MF (2018) Effect of acute exposure to toluene on cortical excitability, neuroplasticity, and motor learning in healthy humans. Arch Toxicol 92(10): 3149-3162.

18. (2012) National Association of Testing Authorities. Guidelines for the validation and verification of quantitative and qualitative test methods. Nata, p. 1-32.

19. Shrivastava A, Gupta V (2011) Methods for the determination of limit of detection and limit of quantitation of the analytical methods. Chronicles Young Sci 2(1): 21-25.

$\begin{array}{ll}\text { BIOMEDICAL } & \text { Assets of Publishing with us } \\ \text { RESEARCHES } & \text { - Global archiving of articles } \\ \text { - Immediate, unrestricted online access }\end{array}$

